\title{
Preparation of Ethyl 4-Nitrobenzoate Using Ultradispersed Natural Zeolite Catalysts, Ultrasound and Microwave Irradiation
}

\author{
Tsiuri Ramishvili ${ }^{*}$, Vladimer Tsitsishvili ${ }^{1}$, Tinatin Bukia² \\ ${ }^{1}$ Petre Melikishvili Institute of Physical and Organic Chemistry, Ivane Javakhishvili Tbilisi State University, Tbilisi, Georgia \\ ${ }^{2}$ San Diego State University Georgia, Tbilisi, Georgia \\ Email: ^tsiuri.ramishvili@tsu.ge, v.tsitsishvili@gmail.com, tinatin.bukia019@ens.tsu.edu.ge
}

How to cite this paper: Ramishvili, T., Tsitsishvili, V. and Bukia, T. (2021) Preparation of Ethyl 4-Nitrobenzoate Using Ultradispersed Natural Zeolite Catalysts, Ultrasound and Microwave Irradiation. Advances in Chemical Engineering and Science, 11, 251-262.

https://doi.org/10.4236/aces.2021.114016

Received: June 16, 2021

Accepted: October 8, 2021

Published: October 11, 2021

Copyright $\odot 2021$ by author(s) and Scientific Research Publishing Inc. This work is licensed under the Creative Commons Attribution International License (CC BY 4.0).

http://creativecommons.org/licenses/by/4.0/

\begin{abstract}
The new possibilities of preparing the ethyl 4-nitrobenzoate by esterification of 4-nitrobenzoic acid (4-NBA) with ethanol under argon at $80^{\circ} \mathrm{C}$ are shown; particularly, over catalysts: on micrometric $(4.8-7.0 \mu \mathrm{m})$ or ultradispersed crystallites $(290-480 \mathrm{~nm}$ ) of hydrogen forms of nanoporous natural zeolites $\mathrm{H}-\mathrm{CL}, \mathrm{H}-\mathrm{MOR}, \mathrm{H}-\mathrm{HEU}-\mathrm{M}, \mathrm{H}-\mathrm{PHI}$ and under irradiation of the reaction mixture with ultrasound (US, $37 \mathrm{kHz}, 330 \mathrm{~W}, 2 \mathrm{~h}$ ) or microwaves (MW, 2450 $\mathrm{MHz}, 300 \mathrm{~W}, 2 \mathrm{~h}$ ). Ultradispersed crystallites of zeolite catalysts were prepared from hydrogen forms of parent natural zeolites by their treatment with US or MW. In the esterification, the synergism of the actions of catalysts and MW or US was revealed; wherein on the ultradispersed best catalysts H-HEU-M and H-MOR conversion of 4-NBA and yield of ethyl 4-nitrobenzoate reached up to $70 \%$ and $67 \%$, respectively. GC/MS, FTIR, NMR methods were used in the study.
\end{abstract}

\section{Keywords}

Ultradispersed Natural Zeolite, Ethyl 4-Nitrobenzoate, Microwaves, Ultrasound

\section{Introduction}

Ethyl 4-nitrobenzoate is a semi-product in the chemical-pharmaceutical industry for the production of local anesthetics-novocaine (procaine, 2-ethylaminoethyl ester of 4-aminobenzoic acid) and anestezin (benzocaine, ethyl ester of 4-aminobenzoic acid), which are also found in other pain relievers [1]-[6]. 
Many methods were described for the preparation of ethyl 4-nitrobenzoate with esterification (Fischer esterification) of 4-nitrobenzoic acid with ethanol (Scheme 1); the reaction is reversible and the catalysts for this process are sulfuric acid [7], ammonium hydrogen sulfate [8], however, this catalyst is not commercially available; polyfluoroalkanesulfonic acid [9], silicon tetrachloride [10]. In all these methods, the yield of ethyl 4-benzoate was $75 \%$ - 98\%. It was shown that in a cascade reactor the esterification of 4-nitrobenzoic acid in the presence of sulfuric acid as a catalyst had some advantages over the same process in a batch reactor [4]. In this case, in a cascade reactor at $110^{\circ} \mathrm{C}-120^{\circ} \mathrm{C}$ in a short time $(10.5 \mathrm{~min})$, the conversion of 4 -nitrobenzoic acid reaches $96 \%$, while in a batch reactor; the same effect is achieved at a higher temperature $\left(180^{\circ} \mathrm{C}\right)$ and within 3 hours.

These specified methods for the production of ethyl 4-nitrobenzoate can be considered ecologically unjustified due to the use of large amounts of sulfuric acid, halogenated solvents, the need to regenerate excess alcohol, the presence of a large amount of wastewater and large losses of the target product.

As our study below shows, in the ethanol esterification reaction of 4-nitrobenzoic acid, the use of solid acidic zeolites in synergy with microwaves and ultrasound is promising.

Today more than three thousand chemical reactions are known that occur under the specific activation during microwaves and ultrasound irradiation. They are based on mechanisms of fast dielectric heating of material [11] and acoustic cavitation [12], respectively. Sonication and microwave chemistry are also important in the field of preparation of nanomaterials [13] [14]; nanoparticles have a large surface-to-volume ratio, display increased surface activity and therefore have versus massive materials (adsorbents, catalysts) a great activity [15] [16]. It was shown that pretreatment of H-MOR and H-BEA zeolites with ultrasound causes a change in the morphology of zeolite crystals (unit cell volume, crystal and particle sizes) and their acidic properties [17].

Also by synergistic action of ultrasound and microwaves during the synthesis of type $\mathrm{Y}$ zeolite, it was succeeded preparation of micro-mesoporous $\mathrm{Y}$ type zeolite in a form of small crystalline nanoparticles, with significantly increased catalytic activity [18].

Due to the synergistic action of microwaves/ultrasound, and catalysts in the esterification and dehydration reactions, an increase in catalytic activity was also observed [19].

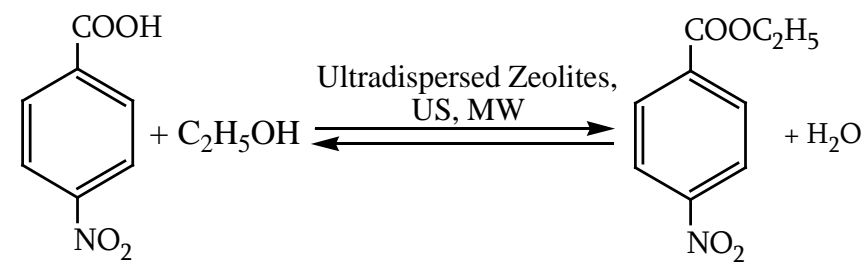

Scheme 1. Reaction for synthesis of ethyl 4-nitrobenzoate. 
In the current study, ethyl 4-nitrobenzoate was prepared in two ways by solvent-free esterification of 4-NBA with ethanol in an argon atmosphere at the boiling point of the reaction mixture; with application of nanoporous acid catalysts-hydrogen forms of natural zeolites: H-CL, H-MOR, H-HEU-M, H-PHI with ultradispersed crystallites $(290-480 \mathrm{~nm})$; as well as by irradiation of the reaction mixture with ultrasound $(37 \mathrm{kHz}, 330 \mathrm{~W}, 2 \mathrm{~h})$ or microwaves $(2450$ $\mathrm{MHz}, 300 \mathrm{~W}, 2 \mathrm{~h}$ ). These methods are simple and environmentally friendly.

\section{Materials and Methods}

\subsection{Chemicals and Materials}

In the study was applied 4-Nitrobenzoic acid ( $\geq 98 \%$, Sigma-Aldrich, USA), ethyl 4-nitrobenzoate ( $\geq 98 \%$, Sigma-Aldrich, USA), ethanol (99.9\%, HPLC, CarlRoth, Germany). Argon (99.999\%) was used as an inert medium during reactions. As heterogeneous catalysts were used solid acids, hydrogen forms of nanoporous natural zeolites clinoptilolite (CL, 95\%, $v(\mathrm{Si}) / v(\mathrm{Al})=4.4)$, mordenite $(\mathrm{MOR}$, $50 \%-60 \%, v(\mathrm{Si}) / v(\mathrm{Al})=6.5$ ), heulandite (as monomineral, HEU-M, $v(\mathrm{Si}) / v(\mathrm{Al})$ $=3.4)$ and phillipsite (PHI, 90\%, $v(\mathrm{Si}) / v(\mathrm{Al})=2.6)$, from Georgian deposits of Dzegvi, Bolnisi-Ratevani, Akhaltsikhe and Shukhuti, respectively. Catalysts were prepared from the corresponding natural zeolites according to the method described in section 2.2 .

\subsection{Preparation of Catalysts}

Catalysts with micrometric crystallites. The catalysts have been prepared from the museum samples of natural zeolites of Georgia. Light pink crystals of monomineral heulandite sample ( $\mathrm{HEU}-\mathrm{M}, \mathrm{SiO}_{2} / \mathrm{AI}_{2} \mathrm{O}_{3}=6.8,0.5 \mathrm{~cm}$ in size) were selected from natural heulandite manually under a binocular microscope. Starting forms of natural zeolites: clinoptilolite (CL), HEU-M, PHI and MOR were ground down to a powder finer than $6 \mu \mathrm{m}$, washed with distilled water and dried. The hydrogen forms of catalysts obtained from them and denoted respectively, H-CL, H-HEU-M, H-PHI, H-MOR were prepared in the way described below.

Catalysts H-CL and H-MOR. Natural CL and MOR were leached once with $1 \mathrm{M}$ HCI solution ( $10 \mathrm{~mL}$ solution/g zeolite) for $3 \mathrm{~h}$ at reflux temperature; the suspension was filtered and the precipitate was washed with hot distilled water until a negative reaction for chlorine ions and dried in air at $40^{\circ} \mathrm{C}$ [16].

Catalysts H-HEU-M and H-PHI. These were prepared also as a catalyst $\mathrm{H}-\mathrm{CL}$ and $\mathrm{H}-\mathrm{MOR}$ from zeolites starting forms HEU-M and PHI; in order to prevent destruction of the HEU-M and PHI crystal structure the $0.25 \mathrm{M}$ solution of hydrochloric acid ( $10 \mathrm{~mL}$ solution/g zeolite) was taken.

Zeolite catalysts with ultradispersed crystallites. For dispersing of micrometric particles of hydrogen forms of the studied zeolites of their suspensions (10\%) in water were subjected to ultrasonic or microwave processing. using for this purpose ultrasonic cleaner (Elma P $120 \mathrm{H}$, Germany, frequency-37 kHz, pow- 
er-330 W) and the Ultrasonic-Microwave (hybrid) reactor UMR-300B, Japan; microwave frequency-2450 MHz, power-300 W), respectively. Ultrasonic radiation of samples was carried out for $7.5 \mathrm{~h}$; at the same time before radiation, it is consecutive in 1, 2, 3 and $7.5 \mathrm{~h}$, measured particle size distribution of zeolites. By ultrasound irradiation water temperature in the ultrasonic cleaner rose up to $55^{\circ} \mathrm{C}$ and it was supported throughout the entire period. Irradiation by microwaves was carried out at $40^{\circ} \mathrm{C}$ for $2 \mathrm{~h}$.

\subsection{Characterization of Catalysts}

By $X$-ray fluorescence analysis using energy dispersive X-ray fluorescence spectrometer EDX3600B (Skyray Instrument Ltd., China) the partial chemical composition of catalysts was determined [16]

Particle size determination. After ultrasonic and microwave treatment the distributions by the sizes of crystallites of catalysts H-CL, H-HEU-M, H-PHI, H-MOR on the laser light scattering particle size analyzer (Laser-Particle Sizer Analysette 12-DynaSizer, Fritsch) by Cumulants and Pade Laplace algorithms were determined. Size distribution was expressed in terms of intensity and volume.

\subsection{Catalytic Activity, Analysis of Reaction Products}

Before the catalytic experiments, the catalysts were heated for 3 hours in a clean airstream at $310^{\circ} \mathrm{C}$ for H-CL, H-MOR and at $210^{\circ} \mathrm{C}$ for H-HEU-M and H-PHI to prevent structural change from heulandite $\mathrm{A}$ to heulandite $\mathrm{B}$ and thermal decomposition of phillipsite at $250^{\circ} \mathrm{C}$.

When using only zeolite catalysts, the reactions were carried out under static conditions in a three-necked flask with a reflux condenser and a thermometer, in an argon atmosphere, on a magnetic stirrer with thermoregulation (MSH-300). The reactions under microwave and ultrasonic irradiation were carried out in a hybrid reactor (UMR-300B) under the same conditions. The regenerated catalyst was added to the flask to a solution of 4-nitrobenzoic acid in hot ethanol and heated to the boiling point of the mixture for several hours; in particular, in the case of zeolite catalysts containing nanosized particles, within 6 hours; while when the reaction mixture was exposed only to radiation (US or MW) or simultaneously to irradiation and a catalyst, for 2 hours.

The solution obtained after the reaction was filtered through a Buchner funnel, the catalyst separated on the funnel was washed with hot ethyl alcohol to remove the reaction mass adsorbed on the catalyst, and wastewater was added to the first filtrate.

The total filtrate obtained (containing the unconverted 4-nitrobenzoic acid, the resulting ethyl 4-nitrobenzoate, ethyl alcohol and water) was added to a 15\% soda solution until a weak alkaline reaction $(\mathrm{pH}=7.5-8)$. At this time the not reacted 4-nitrobenzoic acid is converted to the salt and completely transferred to the aqueous solution, while the top layer contains alcohol and the 4-nitrobenzoic acid ethyl ester. The mixture was kept in a separation funnel at room temperature to separate the organic-containing top layer, which was then distilled to separate 
(detaching) the alcohol. The remaining ethyl 4-nitrobenzoate precipitate was air-dried at $40^{\circ} \mathrm{C}$ to a constant weight and weighed.

The catalytic properties were characterized by the conversion of 4-nitrobenzoic acid, the selectivity of the formation of ethyl 4-nitrobenzoate and yield.

GC-MS analysis (Agilent Technologies, 5890B/5977A, USA) of the esterification reaction products was performed in the $\mathrm{EI}$ mode, $70 \mathrm{eV}$, capillary column HP-5ms, Ultra Inert, $30 \mathrm{~m} \times 0.32 \mathrm{~mm} \times 0.25 \mu \mathrm{m}$, helium $(1.0 \mathrm{~mL} / \mathrm{min})$ as a carrier gas, methanol as solvent; analyzes were carried out in program mode: hold at $80^{\circ} \mathrm{C}$ for $5 \mathrm{~min}$, ramp to $230^{\circ} \mathrm{C}$ at $30^{\circ} / \mathrm{min}$, hold at $230^{\circ} \mathrm{C}$ for $10 \mathrm{~min}$. The identification of the compounds was made by comparing the spectra with NIST 2014 library. The amount of 4-NBA and ethyl 4-nitrobenzoate were determined from their calibration curves.

Fourier transform infrared spectroscopy (FTIR) studies were conducted on a Nicolet ${ }^{\mathrm{TM}}$ iS50 FTIR Spectrometer-Thermo Fisher Scientific in the infrared region $4000-400 \mathrm{~cm}^{-1}$ (scan 32, resolution $4 \mathrm{~cm}^{-1}$ ); band intensities were denominated in transmittance. Analytical sample: finely dispersed powder (1 - $2 \mathrm{mg}$ ).

NMR spectra were recorded on Bruker NMR-400 (400 MHz). Chemical shifts (ppm) are given relative to solvent: references for DMSO were $2.50 \mathrm{ppm}\left({ }^{1} \mathrm{H}-\mathrm{NMR}\right)$ and $39.50 \mathrm{ppm}\left({ }^{13} \mathrm{C}-\mathrm{NMR}\right)$.

\section{Results and Disscussion}

\subsection{Composition and Particle Size Distribution of Catalysts}

Some characteristics of the catalysts are given in Table 1. It can be seen that after the irradiation of the catalysts with microwaves and ultrasound, the sizes of their particles decrease from the parent micrometric-sized catalysts produces ultradispersed samples with particle sizes $290-480 \mathrm{~nm}$.

\subsection{Catalytic Activity}

\subsubsection{Esterification over Micrometric and Ultra Dispersed Zeolite Catalysts}

The main product of the 4-NBA esterification reaction with ethanol by catalytic or MW- and US-assisted reactions was ethyl 4-nitrobenzoate (Figure 1); formation of a minor amount of the diethyl ether-product of the ethanol dehydration reaction was observed.

The results show that irradiation of hydrogen forms of natural zeolites with US or MW causes a decrease in the size of their crystallites from $4.8-7.0 \mu \mathrm{m}$ to $290-480 \mathrm{~nm}$ (Table 1); the catalytic activity of the similarly prepared zeolite catalysts (H-CL, H-MOR, H-HEU-M, H-PHI), containing ultradispersed crystallites, is increased in the esterification reaction 4-NBA with ethyl alcohol compared to their parent forms (Figure 2).

The conversion values of 4-NBA on the parent catalysts H-MOR, H-HEU-M, $\mathrm{H}-\mathrm{CL}$ and $\mathrm{H}-\mathrm{PHI}$ with micrometric particle sizes $(4.80-7.00 \mu \mathrm{m})$, are inferior (Figure 2), but not significantly, to conversion values on catalysts with ultradispersed particles (290 - $480 \mathrm{~nm}$ ); except H-PHI, the conversion degree of 4-NBA 
over this catalysts is $51 \%-58 \%$. In this case, catalysts with a large entrance window size $(0.7-0.8 \mathrm{~nm})$ turned out to be more active than H-PHI with channel sizes of $0.4 \mathrm{~nm}$; in the presence of $\mathrm{H}$-PHI catalyst, the conversion degree of 4-NBA was less: $27 \%-31 \%$.

The effect of decreasing the particle size of the starting catalysts in the esterification of 4-NBA is more pronounced on the values of yield and selectivity for ethyl 4-nitrobenzoate. For example, in the case of ultradispersed H-CL, in comparison with the parent $\mathrm{H}-\mathrm{CL}$, the ethyl 4-nitrobenzoate yield increases from $29.7 \%$ to $46 \%$ - 51\%. On the ultradispersed catalysts, obtained by treatment of parent catalysts with either microwaves or ultrasound, the values of both conversions and yields of the target product ethyl 4-nitrobenzoate are close (Figure 2); its

Table 1. Composition of the catalysts and the average particle size of the hydrogen forms of natural zeolites after their ultrasonic $(300 \mathrm{~W})$ and microwave $(300 \mathrm{~W})$ treatment for 7.5 hours $\left(\right.$ at $55^{\circ} \mathrm{C}$ ) and 1 hour $\left(\right.$ at $40^{\circ} \mathrm{C}$ ), respectively; sample mass: $1 \mathrm{~g}$.

\begin{tabular}{ccccc}
\hline & & \multicolumn{3}{c}{ Particles size, nm } \\
\cline { 3 - 5 } Zeolite catalysts & $v\left(\mathrm{SiO}_{2}\right) / v\left(\mathrm{AI}_{2} \mathrm{O}_{3}\right)$ & Before irradiation & \multicolumn{2}{c}{ After irradiation } \\
\cline { 3 - 5 } & & $5600-5800$ & $300-325$ & $470-480$ \\
H-CL & 23.3 & $6000-6200$ & $350-360$ & $390-400$ \\
H-HEU-M & 8.2 & $4800-5000$ & $290-310$ & $320-330$ \\
H-PHI & 8.0 & $6500-7000$ & $350-370$ & $400-410$ \\
H-MOR & 20.1 & & & ultrasound \\
\hline
\end{tabular}

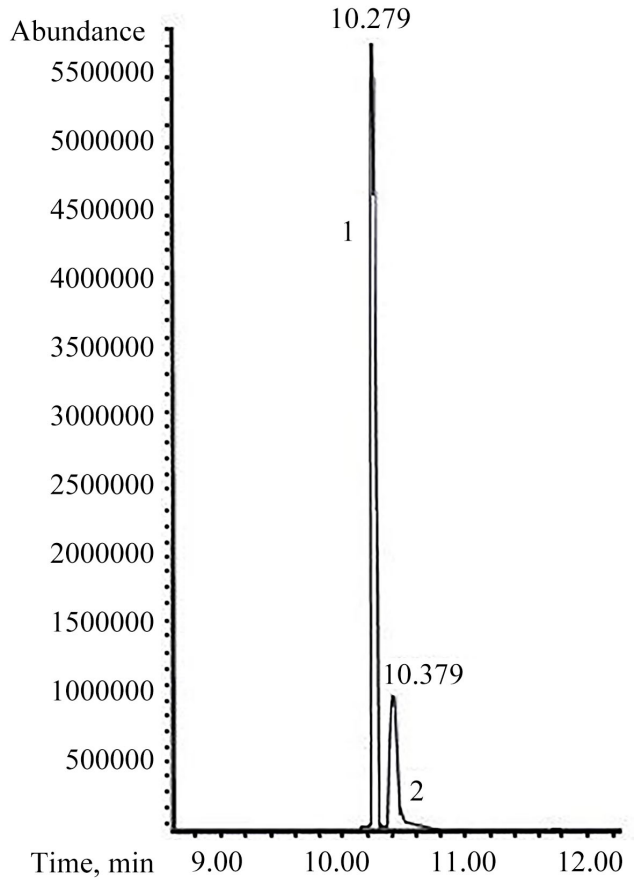

Figure 1. Typical GC/MS chromatogram of the esterification reaction product of 4-NBA with ethanol by the catalytic or US- and MW-assisted conversions at $40^{\circ} \mathrm{C}-80^{\circ} \mathrm{C}$ under argon atmosphere, US or MW (300 W, $\left.2 \mathrm{~h}\right) .1$ : Ethyl 4-nitrobenzoate, $\mathrm{C}_{9} \mathrm{H}_{9} \mathrm{NO}_{4}$, 2: 4-Nitrobenzoic acid, $\mathrm{C}_{7} \mathrm{H}_{5} \mathrm{NO}_{4}$. 


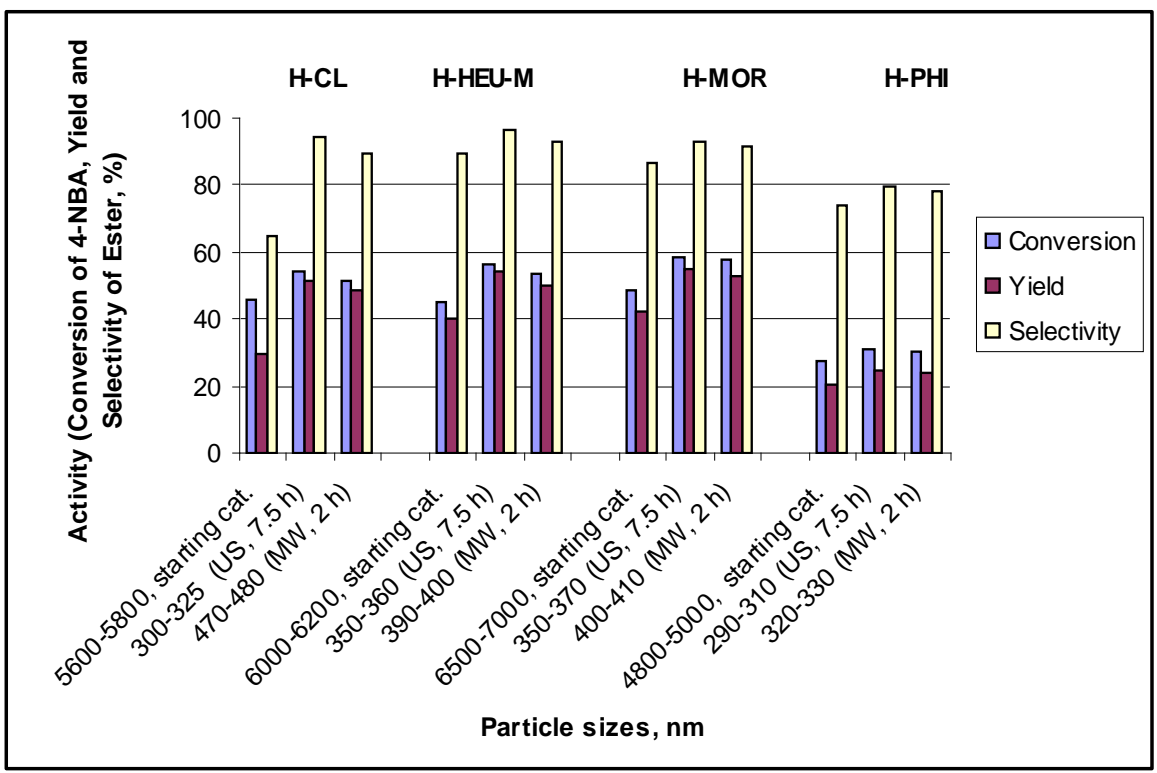

Figure 2. Dependence of the catalytic activity on the particle size for the parent micrometric-sized catalysts (H-CL, H-HEU-M, H-MOR and H-PHI) and their sonicated for $7.5 \mathrm{~h}$ (US, $7.5 \mathrm{~h}$ ) and microwaved for $2 \mathrm{~h}(\mathrm{MW}, 2 \mathrm{~h})$ ultradispersed samples in the esterification of 4-NBA. Mass of catalysts: $0.1 \mathrm{~g}$, mass of 4-NBA: $0.5 \mathrm{~g}$, molar ratio of 4-NBA and ethanol: 1:35; reaction conditions: argon atmosphere, temperature: $80^{\circ} \mathrm{C}$, duration of run: $6 \mathrm{~h}$.

highest yield (about 55\%) is found on H-MOR and H-HEUM.

There is the following selectivity series for the formation of ethyl 4-nitrobenzoate for the initial catalysts at approximately the same conversions of 4-NBA (45\% $49 \%)$

H-HEU-M (89.5\%) > H-MOR (86.5\%) > H-CL (65.0\%).

For the same zeolite catalysts but with ultradispersed particles at comparable conversions of 4-NBA (55\% - 59\%), the selectivity range is as follows:

H-HEU-M (96.5\%) > H-MOR (93.3\%) > H-CL (94.1\%).

On the investigated zeolite catalysts, with the micrometric and ultradispersed particles, in the esterification 4-NBA the obtained series of selectivity in ethyl 4-nitrobenzoate are similar, which indicates the same nature of the active centers in them.

\subsubsection{Sinergic Action Ultradispersed Natural Zeolites and Ultrasonic or Microwave Radiations in Esterification}

When the 4-NBA was irradiated only with ultrasound or microwaves, the selectivity of the formation of ethyl-4-nitrobenzoate (about 93\%) and the conversion of 4-NBA (about 58\%) are the same as in the case of ultradispersed zeolites H-HEU-M, H-MOR, H-CL (Table 2); these parameters exceed those for the parent micrometric zeolites (Figure 2).

In the esterification reaction of 4-NBA with the simultaneous action of ultrasound or microwaves and as a catalysts hydrogen forms of natural zeolites with ultradisperse particles, the process is accelerated in comparison with the thermocatalytic reaction; in particular, for the most active ultradispersed catalysts 
Table 2. Effect of ultrasound $(300 \mathrm{~W}, 37 \mathrm{kHz})$ and microwave $(300 \mathrm{~W}, 2450 \mathrm{MHz})$ irradiation on the esterification reaction of 4-nitrobenzoic acid, and effect of these irradiations together with catalysts-hydrogen forms of natural zeolites with ultradispersed particles; $\mathrm{m}(4-\mathrm{NBA})=0.5 \mathrm{~g}$, catalyst weight: $0.1 \mathrm{~g}$, molar ratio $\mathrm{v}(4-\mathrm{NBA}) / \mathrm{v}\left(\mathrm{C}_{2} \mathrm{H}_{5} \mathrm{OH}\right)$ $=1 / 35$, reaction atmosphere: argon, reaction temperature: $80^{\circ} \mathrm{C}$, reaction run time: $2 \mathrm{~h}$.

\begin{tabular}{cccc}
\hline Entry & 1 & 2 & 3 \\
\hline $\begin{array}{c}\text { Irradiation type (frequency and } \\
\text { power)/catalysts (particle size, } \\
\text { nm) }\end{array}$ & $\begin{array}{c}\text { Conversion } \\
\text { of } 4 \text {-NBA, \% }\end{array}$ & $\begin{array}{c}\text { Yield of Ethyl } \\
\text { 4-Nitrobenzoate, \% }\end{array}$ & $\begin{array}{c}\text { Selectivity } \\
\text { of Ethyl 4- } \\
\text { Nitrobenzoate, \% }\end{array}$ \\
\hline US (37 kHz, 330 W) & 57.1 & 52.7 & 92.2 \\
MW (2450 MHz, 300 W) & 58.6 & 54.8 & 93.4 \\
US/H-CL (300 - 325) & 61.5 & 58.1 & 94.5 \\
MW/H-CL (470 - 480) & 69.4 & 64.9 & 93.5 \\
US/H-HEU-M (350 - 360) & 66.4 & 61.2 & 92.2 \\
MW/H-HEU-M (390 - 400) & 68.1 & 65.6 & 96.3 \\
US/H-PHI (290 - 310) & 34.7 & 28.0 & 80.7 \\
MW/H-PHI (320 - 330) & 36.7 & 32.5 & 88.6 \\
US/H-MOR (350 - 370) & 69.6 & 66.4 & 95.4 \\
MW/H-MOR (400 - 410) & 70.3 & 67.4 & 95.9 \\
\hline
\end{tabular}

H-MOR and H-HEU-M, the degree of 4-NBA conversion increases to $70 \%$ and the yield of ethyl 4-nitrobenzoate to $67 \%$ (Table 2).

\subsubsection{Identification of Synthesized Ethyl 4-Nitrobenzoate}

Synthesized ethyl 4-nitrobenzoate was identified by its melting point, GC/MS, FTIR, ${ }^{1} \mathrm{H}$ and ${ }^{13} \mathrm{C}$ NMR spectra. Melting point of ethyl 4-NBA samples prepared on zeolite catalysts $\mathrm{H}-\mathrm{CL}, \mathrm{H}-\mathrm{HEU}$ and $\mathrm{H}-\mathrm{HEU}-\mathrm{M}$, and re-crystallized in ethanol was equal to $55^{\circ} \mathrm{C}-57^{\circ} \mathrm{C}$.

The FTIR spectra of initial 4-Nitrobenzoic acid and Ethyl 4-nitrobenzoate, synthesized by synergic action of H-MOR (400 - $410 \mathrm{~nm}$ ) and MW (300 W, $2450 \mathrm{MHz}$ ) irradiation, are shown in Figure 3; the strongest peak for ethyl 4-nitrobenzoate is $1712.26 \mathrm{~cm}^{-1}$ which corresponds to the $\mathrm{C}=\mathrm{O}$ ester peak region; conjugation with an aromatic ring shifts the peak characteristic of the $\mathrm{C}=\mathrm{O}$ group from $1750-1735 \mathrm{~cm}^{-1}$ to $1712.26 \mathrm{~cm}^{-1}$. Peaks at $1366.77,1520.06$, $869.81,711.51$ and $505.53 \mathrm{~cm}^{-1}$ correspond to the $\mathrm{NO}_{2}$ group [20]. Two strong spectral bands at 1269.03 and $1100.94 \mathrm{~cm}^{-1}$ correspond to the symmetric and antisymmetric $\mathrm{C}-\mathrm{O}$ stretches of the ester $\mathrm{COO}$ group and the band at 1008.72 $\mathrm{cm}^{-1}$ is the ether CO stretch of the OC2H5 group [21] [22]. The presence in the FTIR spectrum of said characteristic frequencies and their comparison with the spectrum of the starting 4-nitrobenzoic acid unambiguously indicates the formation of Ethyl 4-nitrobenzoate (Figure 3), which corresponds to the standard ethyl 4-nitrobenzoate FTIR spectrum [23].

The NMR spectra data of the prepared ethyl 4-nitrobenzoate was as follows. 


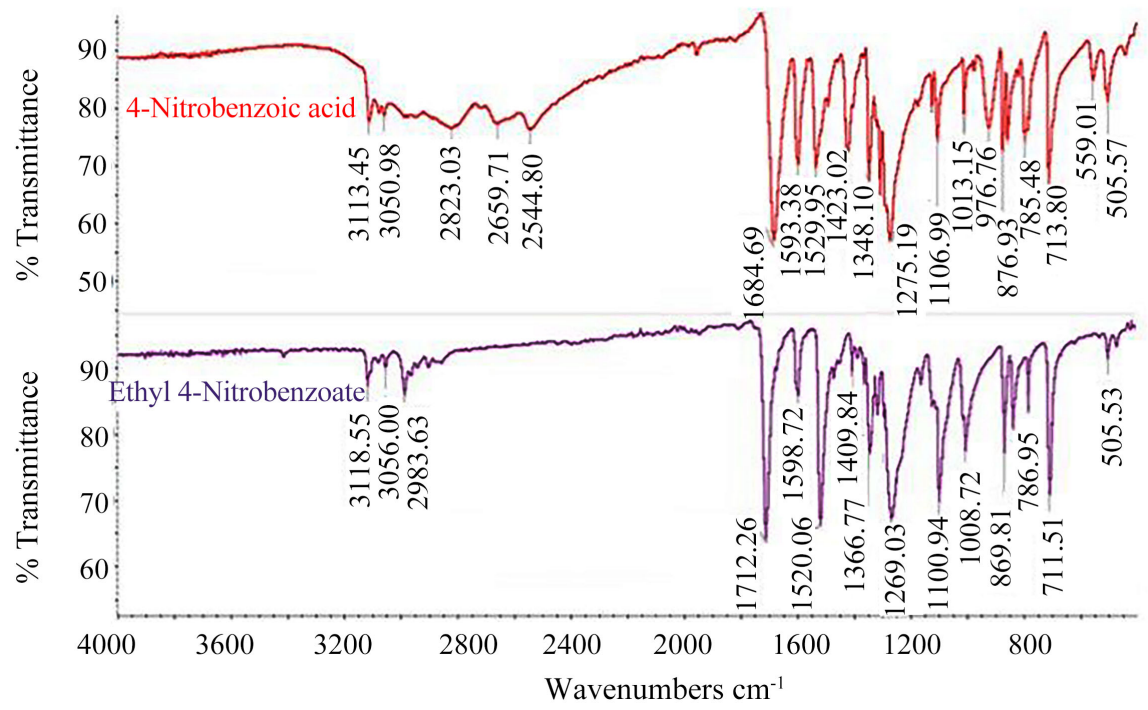

Figure 3. FTIR spectra of parent 4-Nitrobenzoic acid and Ethyl 4-nitrobenzoate, synyhesized by synergic action of H-MOR (400 - $410 \mathrm{~nm})$ and MW (300 W, $2450 \mathrm{MHz})$ irradiation in esterification reaction of 4 -Nitrobenzoic acid; $\mathrm{m}(\mathrm{H}-\mathrm{MOR})=0.1 \mathrm{~g}$, molar ratio $\mathrm{v}(4-\mathrm{NBA}) / \mathrm{v}\left(\mathrm{C}_{2} \mathrm{H}_{5} \mathrm{OH}\right)=1 / 35$, reaction atmosphere: argon, reaction temperature: $80^{\circ} \mathrm{C}$, duration of run: $2 \mathrm{~h}$.

${ }^{1} \mathrm{H}$ NMR (400 MHz, DMSO-d6): $\delta 8.35-8.34(2 \mathrm{H}, \mathrm{m}), 8.21-8.18(2 \mathrm{H}, \mathrm{m})$, $4.41-4.35(\mathrm{q}, 2 \mathrm{H}, \mathrm{J}=7.1 \mathrm{~Hz}), 1.37-1.34(\mathrm{t}, 3 \mathrm{H}, \mathrm{J}=7.1 \mathrm{~Hz})$;

${ }^{13} \mathrm{C}$ NMR (100 MHz, DMSO-d6) $\delta(\mathrm{ppm}) 164.77(\mathrm{C}=\mathrm{O}), 150.70\left(\mathrm{C}-\mathrm{NO}_{2}\right)$, 135.76, 131.07 (2C), 124.37, 62.15, 14.51 .

This NMR spectra $\left({ }^{1} \mathrm{H}\right.$ NMR and ${ }^{13} \mathrm{C}$ NMR) data of ethyl 4-nitrobenzoate, synthesized on the zeolite catalysts and under influence of US or MW irradiation, completely coincide with the literature data [23].

\section{Conclusion}

1) The synthesis reaction of ethyl 4-nitrobenzoate was investigated by esterification of 4-nitrobenzoic acid with ethanol under argon at the boiling point of the reaction mixture; heterogeneous catalytic synthesis is carried out in the presence of acidic catalysts, hydrogen forms of natural zeolites: H-CL, H-MOR, H-HEU-M, H-PHI with ultradispersed crystallites (290 - $480 \mathrm{~nm}$ ); and also ethyl 4-nitrobenzoate was synthesized by irradiation of the reaction mixture with ultrasound $(37 \mathrm{kHz}, 330 \mathrm{~W}, 2 \mathrm{~h})$ or microwaves $(2450 \mathrm{MHz}, 300 \mathrm{~W}, 2 \mathrm{~h})$. Ethyl 4-nitrobenzoate is identified by GC/MS, FTIR and NMR $\left({ }^{1} \mathrm{H},{ }^{13} \mathrm{C}\right)$ spectroscopy.

2) Zeolite catalysts with ultradispersed crystallites were prepared from hydrogen forms of parent natural zeolites with micrometric crystallites $(4.8-7.0 \mu \mathrm{m})$ by their indirect treatment with ultrasound (US, $300 \mathrm{~W}, 37 \mathrm{kHz}, 7.5 \mathrm{~h}$ ) or by direct influence of microwaves (MV, $300 \mathrm{~W}, 2450 \mathrm{MHz}, 2 \mathrm{~h}$ ) on the catalysts; these irradiations cause a reduction in the size of zeolite crystallites as determined by means of the laser light scattering particle size analyzer. The zeolite catalysts particle sizes obtained by both types of irrradiations are close to each other and the 
particle size was in a range of $290-480 \mathrm{~nm}$.

3) The 4-NBA conversion, ester yield and selectivity are higher on zeolite catalysts with ultradispersed particles than on catalysts with micrometric crystallites. Thus, the size effect is observed here. With the simultaneous exposure of the reaction mixture to irradiation (ultrasound or microwaves) and ultradispersed zeolite catalysts, there is a synergistic effect; catalysts activity increases and on the best of them (H-MOR and H-HEU-M) conversion and yield of ethyl 4-nitrobenzoate reach up to $70 \%$ and $67 \%$, respectively.

The activities (conversion, yield) of one ultrasound or microwaves in the esterification of 4-NBA are comparable with the activity of ultradispersed catalysts, but in the latter, the reaction time is three times longer $(6 \mathrm{~h})$.

4) In contrast to the known methods for the production of ethyl 4-nitrobenzoate, which use halogen-containing solvents, catalysts that are aggressive for the environment (sulfuric acid, ammonium hydrogen sulfate, sulfuryl chloride, polyfluoroalkanesulfonic acid) and complex apparatus design, esterification of 4-NBA under the influence of ultrasound, microwaves or ultradispersed natural zeolites is a simple and cheap way.

The use of microwaves, ultrasound or catalysts of ultra-dispersed natural zeolites allows the successful synthesis of ethyl 4-nitrobenzoate in an argon atmosphere at about $80^{\circ} \mathrm{C}$ without the use of solvents, aggressive substances and multistage processes; at the same time, providing conversions of about 60 - 70 and yields of $55 \%-67 \%$, as well as a high selectivity (more than $90 \%$ ) according to the ester.

\section{Conflicts of Interest}

The authors declare no conflicts of interest regarding the publication of this paper.

\section{References}

[1] Vardanyan, R.S. and Hruby, V.J. (2006). Synthesis of Essential Drugs. 1st Edition, Elsevier, Amsterdam. https://doi.org/10.1016/B978-044452166-8/50036-4

[2] Klyuev, M.V., Abdullaev, M.G. and Abdullaeva, Z.S. (2010) Palladium Catalysts in the Synthesis of Local Anesthetics (Review). Pharmaceutical Chemistry Journal, 44, 446-451. https://doi.org/10.1007/s11094-010-0487-5

[3] Roodan, S.M. and Ghaderi, A. (2019) Copper-Catalyzed Demethylative Esterification of Arylmethylketones: A New Route for the Synthesis of Benzocaine. Journal of the Iranian Chemical Society, 16, 2327-2332. https://doi.org/10.1007/s13738-019-01698-Z

[4] de França, A.S., Leão, R.A.C. and de Souza, R.O.M.A. (2020) Two Step Continuous-Flow Synthesis of Benzocaine. Journal of Flow Chemistry, 10, 563-569. https://doi.org/10.1007/s41981-020-00098-2

[5] Liu, Q.L. (2016) Synthesis Method of Benzocaine. CN Patent No. 106699579A. https://patents.google.com/patent/CN106699579A/en

[6] Azev, Y.A., Charushnikov, K.A., Giber, A.M., et al. (2014) Sposob Poluchenia Anestezina. Patent RU 2505526. (In Russian) https://www1.fips.ru/fips_servl/fips_servlet?DB=RUPAT\&DocNumber=2505526\&T 
ypeFile $=$ html

[7] Berkengeim, A.M. (1942) Praktikum po sinteticheskim lekarstvennim I dushistim veshchestvam I fotoreaktivam. Gosudarstvennoe Nauchno-technicheskoe izdatelstvo chimicheskoi literature, Moskva-Leningrad. (In Russian) https://sng1lib.org/book/532973/975520?id=532973\&secret $=975520$

[8] Elgazin, S.A., Ivanov, B.K.,Tiuvanova, A.P., et al. (1975) Sposob polychenia etilovogo efira nitrobenzoinoi kisloti. Patent SU 455943A1. (In Russian) https://patenton.ru/patent/SU455943A1

[9] Papenfuhs, T., Hess, R. and Fuss, A. (2010) Process for the Preparation of Alkyl Nitrobenzoates. US 5087725A. https://patents.google.com/patent/US5087725A/en

[10] Matveev, L.G., Bolshakov, I.I. and Sheverdova, N.Y. (1997) Sposob poluchenia etilovogo efira p-nitrobenzoinoi kisloti. Patent RF 2074169. (In Russian)

https://yandex.ru/patents/doc/RU2074169C1_19970227

[11] Kappe, C.O., Dallinger, D. and Murphree, S. (2009) Practical Microwave Synthesis for Organic Chemists. Wiley-VCH, Weinheim. https://doi.org/10.1002/9783527623907

[12] Chatel, G. (2017) Sonochemistry: New Opportunities for Green Chemistry. World Scientific Europe Ltd., London. https://doi.org/10.1142/q0037

[13] Horikoshi, S. and Serpone N. (2013) Microwaves in Nanoparticle Synthesis: Fundamentals and Applications. Wiley-VCH Verlag GmbH, Baden. https://doi.org/10.1002/9783527648122

[14] Tsuji, M., Hashimoto, M., Nishizawa, Y., Kubokawa, M. and Tsuji, T. (2005). Microwave-Assisted Synthesis of Metallic Nanostructures in Solution. Chemistry: A European Journal, 11, 440-452. https://doi.org/10.1002/chem.200400417

[15] Sharma, N., Sharma, U.K. and Van der Eycken, E.V. (2018) Microwave-Assisted Organic Synthesis: Overview of Recent Applications. In: Zhang, W. and Cue, B.W., Eds., Green Techniques for Organic Synthesis and Medicinal Chemistry, Second Edition, John Wiley \& Sons Ltd., New Jersey, 441-468.

https://doi.org/10.1002/9781119288152.ch17

[16] Ramishvili, T.S., Tsitsishvili, V., Chedia, R., Sanaia, E., Gabunia, V. and Kokiashvili, N. (2017) Preparation of Ultradispersed Crystallites of Modified Natural Clinoptilolite with the Use of Ultrasound and Its Application as a Catalyst in the Synthesis of Methyl Salicylate. American Journal of Nano Research and Applications, 5, 26-32. http://article.sciencepublishinggroup.com/html/10.11648.j.nano.s.2017050301.17.ht $\underline{\mathrm{ml}}$

[17] Solyman, S.M., Noha, A.-G.A.K., Tawfik, F.M., Sadek M., Ahmed, H.A. and Solyman, S.M. (2013) Performance of Ultrasonic-Treated Nano-Zeolites Employed in the Preparation of Dimethyl Ether. Egyptian Journal of Petroleum, 22, 91-99. https://doi.org/10.1016/j.ejpe.2012.09.003

[18] Fu, X., et al. (2016) Ultrasonic/Microwave Synergistic Synthesis of Well-Dispersed Hierarchical Zeolite Y with Improved Alkylation Catalytic Activity. Korean Journal of Chemical Engineering, 33, 1931-1937. https://doi.org/10.1007/s11814-016-0022-9

[19] Reilly, M.K., King, R.P., Wagner, A.J. and King, S.M. (2014) Microwave-Assisted Esterification: A Discovery-Based Microscale Laboratory Experiment. Journal of Chemical Education, 91, 1706-1709. https://doi.org/10.1021/ed400721p

[20] Samsonowicz, M., Świsłocka, R. and Regulska, E. (2007) Experimental and Theoretical IR, Raman, NMR Spectra of 2-, 3-, and 4-Nitrobenzoic Acids. International Journal of Quantum Chemistry, 107, 480-494. https://doi.org/10.1002/qua.21085

[21] Smith, B.C. (2018) The C=O Bond, Part VI: Esters and the Rule of Three. Spectroscopy 
Online.

https://www.spectroscopyonline.com/view/co-bond-part-vi-esters-and-rule-three

[22] Smith, B.C. (2011) Fundamentals of Fourier Transform Infrared Spectroscopy. 2nd Edition. CRC Press, Boca Raton. https://doi.org/10.1201/b10777

[23] Spectral Database for Organic Compounds, SDBS.

https://sdbs.db.aist.go.jp/sdbs/ 